\title{
Variation in the fat mass and obesity-related (FTO) genotype is not associated with body fatness in infants, but possibly with their length
}

Pontus Henriksson, M. Lof, Peter Söderkvist and Elisabet Forsum

\author{
Linköping University Post Print
}

\section{Tweet}

N.B.: When citing this work, cite the original article.

Original Publication:

Pontus Henriksson, M. Lof, Peter Söderkvist and Elisabet Forsum, Variation in the fat mass and obesity-related (FTO) genotype is not associated with body fatness in infants, but possibly with their length, 2014, Pediatric Obesity, (9), 5, E112-E115.

http://dx.doi.org/10.1111/ijpo.231

Copyright: Wiley: 12 months

http://eu.wiley.com/WileyCDA/

Postprint available at: Linköping University Electronic Press

http://urn.kb.se/resolve?urn=urn:nbn:se:liu:diva-112052 
Variation in the fat mass and obesity related (FTO) genotype is not associated with body fatness in infants, but possibly with their length.

Pontus Henriksson ${ }^{1}$, Marie Löf ${ }^{2}$, Peter Söderkvist ${ }^{1}$ and Elisabet Forsum ${ }^{1}$

${ }^{1}$ Department of Clinical and Experimental Medicine, Linköping University, SE 58185

Linköping, Sweden.

${ }^{2}$ Department of Biosciences and Nutrition, Karolinska Institute, NOVUM, SE 14183 Huddinge, Sweden.

Correspondence: P Henriksson, Division of Nutrition, Department of Clinical and Experimental Medicine, Linköping University, SE 58185 Linköping, Sweden. E-mail: Pontus.Henriksson@liu.se, Phone: +46-10-1034743.

Last names of authors: Henriksson, Löf, Söderkvist, Forsum

Abbreviations: BMI, body mass index; FFM, fat free mass; FM, fat mass; FTO fat mass and obesity; PATHOS, Parents And THeir Offspring Study

Key words: body composition, fat mass, FTO, infant

Running title: FTO vs. infant size and body composition 


\begin{abstract}
Background: Data relating variation at the fat mass and obesity related (FTO) locus (rs9939609) to fat mass in infancy are inconclusive.

Objective: To study relationships between FTO-genotype and infant size (at 1 and 12 weeks and at 1 year of age) and body composition (at 1 and 12 weeks).
\end{abstract}

Methods: Body composition was assessed using air displacement plethysmography in 207 infants. FTO was genotyped using the TaqMan assay.

Results: The number of risk alleles was related to length at 1 and 12 weeks $(P=0.007-0.033)$ but not to fat mass. The relationship to length was stronger in boys than in girls.

Conclusions: Our results suggest that the FTO-genotype is not related during infancy to fat mass but is related to length in boys but not in girls. 


\section{Introduction}

Obesity is influenced by genetics (1), and variation at the fat mass and obesity related locus (FTO) is related to body mass index (BMI) and fat mass (FM) in children and adults $(2,3)$. In these studies addition of each risk allele at the single nucleotide polymorphism, rs9939609, was associated with a higher BMI or with more FM. Several studies report no such relationship in infants (4-6), and Sovio et al. even found an inverse association between the FTO-genotype and BMI below 2.5 years of age (7). In infancy, when BMI is a poor predictor of FM (8), studies relating the FTO-genotype to body composition are more relevant, but few such studies have been published. However, López-Bermejo et al. (9) reported a positive relationship between the number of risk alleles and FM in 2-week-old infants, while MookKanamori et al. (6) found no such relationship at 6 months. In this longitudinal study, our aims were to relate the FTO-genotype to body size and composition in infants aged 1 and 12 weeks and to their weight and length at 1 year of age.

\section{Methods}

Healthy, singleton and full term ( $\geq 37$ gestational weeks) infants of healthy mothers participated in PATHOS (Parents And THeir Offspring Study). Parents (>90\% Caucasians) were recruited from a well-educated Swedish population between 2008 and 2010. Overweight and obesity were present in $21 \%$ and $43 \%$ of mothers and fathers, respectively. Infant size and body composition, assessed using air displacement plethysmography (8), were measured at 1 and 12 weeks of age. Parents reported weight and length of their 1-year-old infants after visiting a health clinic. Mode of feeding and parity were recorded. Gestational age was based on an ultrasound examination (10). The Regional Ethics Committee, Linköping, Sweden, approved the study and parents gave informed consent. Saliva was collected from infants and DNA was extracted using QuickExtract DNA Extraction Solution 1.0 (Epicentre 
Biotechnologies, Madison, WI, USA). Genotyping, i.e. assessing the number of risk (A) or wild type (T) alleles at the FTO locus rs9939609, was based on real-time PCR (polymerase chain reaction) using the TaqMan Genotyping Assay (ID: C__30090620_10) and was analysed on a ABI Prism 7900HT “Sequence Detection System” (Applied Biosystems, Carlsbad, CA, USA). Call rate was 99\% (207/209). Regression analysis (11) was used assuming an additive effect of FTO. Reported models were adjusted for maternal parity, infant sex, gestational age at birth and age at measurement. A previous study (12) suggested that the sexes respond differently to the FTO-genotype. Therefore, an interaction term (FTO x sex) was entered in the regression models. Values are means and standard deviations (SD). All hypothesis tests were two-sided and significance was accepted when $P<0.05$. Statistical analysis was conducted using PASW Statistics 18 (IBM, Sowers, NY, USA).

\section{Results and Discussion}

Table 1 shows infant characteristics. Table 2 shows relationships between the FTO-genotype, on the one hand, and infant size and body composition on the other hand. No significant relationships were found for BMI or FM. Additional adjustment for maternal BMI before pregnancy had minor effects on the results (data not shown). Our findings disagree with data reported by López-Bermejo et al. (9), but are in agreement with results reported by MookKanamori et al. (6). These studies $(6,9)$ assessed body composition using dual x-ray absorptiometry, a method requiring careful standardization. The number of risk alleles was positively related $(P<0.05)$ to fat free mass and weight at 1 and 12 weeks of age. However, these relationships were not significant when adjusted for infant length, suggesting that these observed effects can be explained by an effect on length. Thus we found a positive relationship between the number of risk alleles and length at $1(P=0.033)$ and $12(P=0.007)$ weeks but not at 1 year of age $(P=0.052)$. Earlier studies reported no such relationships $(6,9)$ 
but one study (13), which used a risk score based on several obesity associated loci including FTO (rs9939609), showed this score to be associated with length at 6 weeks of age.

The interaction term (FTO x sex) was significant $(P=0.047)$ when length at 12 weeks was the dependent variable (Table 2). The corresponding interactions were weaker at 1 week $(P=0.067)$ and 1 year $(P=0.11)$ of age. However, these interactions were significant in unadjusted models $(P=0.024-0.048)$. Furthermore, for boys, but not for girls $(P=0.59-0.98)$, the number of risk alleles was positively related to length at the age of 1 week $(P=0.004), 12$ weeks $(P=0.001)$ and 1 year $(P=0.012)$.

Strengths of this study include accurate body composition data (14) and that results were adjusted for relevant confounders $(8,15-17)$. Our sample size is similar to previous studies $(6,9)$ but small for this kind of study, which is our main limitation. Furthermore, we cannot exclude that antenatal confounding by maternal genotype has affected our results. Obviously, our findings regarding a relationship between FTO-genotype and length of infant boys need confirmation. We encourage researchers to investigate this relationship since accelerated growth in infancy is a risk factor for later obesity (18).

\section{Acknowledgements}

All authors approved the manuscript and contributed to the study although PH had primary responsibility. There were no conflicts of interest. Participants and co-workers Molbaek, Yamada-Fowler, Johansson, Schippert and Flinke, are gratefully acknowledged. The Swedish Research Council (15402) and the County Council of Östergötland provided funding. 
Table 1. Characteristics of girls ${ }^{*}$ and boys ${ }^{\dagger}$ in the study at 1 and 12 weeks as well as at 1 year of age.

\begin{tabular}{|c|c|c|c|c|c|c|}
\hline & \multicolumn{2}{|c|}{1 week of age } & \multicolumn{2}{|c|}{12 weeks of age } & \multicolumn{2}{|c|}{1 year of age } \\
\hline & Girls $(n=97)$ & Boys $(n=110)$ & Girls ( $\mathrm{n}=97)$ & Boys $(n=110)$ & Girls $(n=96)$ & Boys $(n=109)$ \\
\hline Age (week) & $1.0 \pm 0.3$ & $1.1 \pm 0.3$ & $12.1 \pm 0.4$ & $12.1 \pm 0.4$ & $53.1 \pm 2.4$ & $52.7 \pm 2.1$ \\
\hline Length $(\mathrm{cm})$ & $51.0 \pm 1.5$ & $52.0 \pm 2.0$ & $60.5 \pm 2.0$ & $62.0 \pm 2.0$ & $75.5 \pm 2.5^{\ddagger}$ & $77.0 \pm 2.5^{\ddagger}$ \\
\hline Length-for-age z-score ${ }^{\S}$ & $0.24 \pm 1.12$ & $0.15 \pm 1.11$ & $0.32 \pm 0.97$ & $0.27 \pm 1.12$ & $0.31 \pm 0.95$ & $0.45 \pm 0.94$ \\
\hline Weight (g) & $3515 \pm 438$ & $3682 \pm 497$ & $5856 \pm 573$ & $6427 \pm 858$ & $9700 \pm 940$ & $10580 \pm 1070$ \\
\hline Weight-for-age z-score ${ }^{\S}$ & $-0.15 \pm 0.99$ & $-0.15 \pm 1.09$ & $-0.20 \pm 0.87$ & $0.13 \pm 1.17$ & $-0.14 \pm 0.98$ & $0.11 \pm 1.07$ \\
\hline BMI $\left(\mathrm{kg} / \mathrm{m}^{2}\right)$ & $13.4 \pm 1.1$ & $13.6 \pm 1.2$ & $15.9 \pm 1.1$ & $16.8 \pm 1.7$ & $17.0 \pm 1.3^{\ddagger}$ & $17.7 \pm 1.4^{\ddagger}$ \\
\hline FFM (g) & $3042 \pm 312$ & $3245 \pm 339^{\text {Il }}$ & $4263 \pm 364$ & $4750 \pm 463^{\mathbb{I}}$ & - & - \\
\hline FM (g) & $473 \pm 172$ & $411 \pm 190^{\mathbb{I}}$ & $1593 \pm 356$ & $1623 \pm 440^{\mathbb{T I}}$ & - & - \\
\hline $\mathrm{FM}(\%)$ & $13.2 \pm 3.6$ & $10.9 \pm 4.1^{\mathbb{I I}}$ & $27.0 \pm 4.2$ & $25.2 \pm 4.5^{\mathbb{I}}$ & - & - \\
\hline Any breastfeeding (\%) (n) & $100(97)$ & $100(110)$ & $96.9(94)$ & $96.4(106)$ & - & - \\
\hline
\end{tabular}

Continued... 
Table 1, continued.

Mean \pm SD. BMI, body mass index; FFM, fat free mass; FM, fat mass.

* Girls were born after 40.0 \pm 1.2 gestational weeks. They weighed $3530 \pm 450 \mathrm{~g}$ at birth, $33.0 \%(\mathrm{n}=32)$ had no risk allele (TT), 45.4\% (n=44) had one risk allele (AT), and $21.6 \%$ (n=21) had two risk alleles (AA) for FTO (rs9939609). These frequencies were in Hardy-Weinberg equilibrium $(P=0.73)$.

${ }^{\dagger}$ Boys were born after 40.1 \pm 1.2 gestational weeks. They weighed $3680 \pm 490 \mathrm{~g}$ at birth, $38.2 \%(\mathrm{n}=42)$ had no risk allele $(\mathrm{TT})$, $44.5 \%(\mathrm{n}=49)$ had one risk allele (AT), and $17.3 \%$ (n=19) had two risk alleles (AA) for FTO (rs9939609). These frequencies were in Hardy-Weinberg equilibrium $(P=0.53)$.

* Reported by parents after a visit to a health clinic.

$\S$ Calculated using Swedish reference data (16).

II $\mathrm{n}=108$. 
Table 2. Results of regression analysis relating the number of FTO (rs9939609) risk alleles (0, 1 or 2) as independent variable to body size and composition (dependent variables) for 207 infants at 1 and 12 weeks as well as at 1 year of age.

\begin{tabular}{|c|c|c|c|c|c|c|c|c|c|c|c|c|}
\hline \multirow{2}{*}{$\begin{array}{l}\text { Dependent } \\
\text { variable }\end{array}$} & \multicolumn{4}{|c|}{1 week of age ${ }^{*}$} & \multicolumn{4}{|c|}{12 weeks of age } & \multicolumn{4}{|c|}{1 year of age ${ }^{*}$} \\
\hline & $\mathrm{n}$ & $\mathrm{b}$ & $r^{2}$ & $P$ & $\mathrm{n}$ & $\mathrm{b}$ & $r^{2}$ & $P$ & $\mathrm{n}$ & $\mathrm{b}$ & $r^{2}$ & $P$ \\
\hline Length $^{\dagger}(\mathrm{cm})$ & 207 & 0.31 & 0.023 & $0.033^{*}$ & 207 & 0.47 & 0.036 & $0.007^{\star}$ & 205 & 0.41 & 0.019 & 0.052 \\
\hline Girls & 97 & 0.01 & 0.000 & 0.98 & 97 & 0.08 & 0.001 & 0.76 & 96 & 0.04 & 0.000 & 0.90 \\
\hline Boys & 110 & 0.56 & 0.078 & 0.004 & 110 & 0.77 & 0.096 & 0.001 & 109 & 0.73 & 0.059 & 0.012 \\
\hline Weight $^{\dagger}(\mathrm{g})$ & 207 & 93.3 & 0.030 & $0.014^{\S}$ & 207 & 149.3 & 0.023 & $0.033^{\S}$ & 205 & 0.22 & 0.024 & $0.028^{\S}$ \\
\hline BMI $\left(\mathrm{kg} / \mathrm{m}^{2}\right)$ & 207 & 0.18 & 0.016 & 0.071 & 207 & 0.14 & 0.005 & 0.32 & 205 & 0.18 & 0.009 & 0.17 \\
\hline FFM (g) & 205 & 56.4 & 0.022 & $0.036^{\S}$ & 205 & 103.3 & 0.034 & $0.008^{\S}$ & & & & \\
\hline FM (g) & 205 & 22.7 & 0.010 & 0.16 & 205 & 8.1 & 0.000 & 0.83 & & & & \\
\hline $\mathrm{FM}(\%)$ & 205 & 0.36 & 0.005 & 0.31 & 205 & -0.23 & 0.002 & 0.57 & & & & \\
\hline
\end{tabular}

Continued... 


\section{Table 2, continued.}

$\mathrm{b}$, slope of regression line (effect per risk allele); $\mathrm{r}^{2}$, coefficient of determination calculated from partial r; $P, P$-value; BMI, body mass index; FFM, fat free mass; FM, fat mass.

* FTO was coded as: 0, no risk allele; 1, one risk allele; 2, two risk alleles. Thus the regression analysis assumed an additive effect of the number of risk alleles. Models were adjusted for maternal parity, infant gestational age at birth, infant age at measurement and infant sex (except when the sexes are analyzed separately).

${ }^{\dagger}$ Length and weight at the age of 1 year were reported by parents after a visit to a health clinic.

$\$ P$ for sex-interaction (i.e. number of FTO, rs 9939609, risk alleles x sex) was 0.067 (1 wk), 0.047 (12 wk), 0.11 (1 y). Furthermore, when including a sex-interaction (together with infant sex) in unadjusted models the corresponding $P$-values were: 0.026 ( 1 wk), 0.024 (12 wk), 0.048 (1 y).

$\S$ Not significant $(P \geq 0.19)$ when adjusted for infant length. 


\section{REFERENCES}

1. Maes HH, Neale MC, Eaves LJ. Genetic and environmental factors in relative body weight and human adiposity. Behav Genet 1997;27:325-51.

2. Frayling TM, Timpson NJ, Weedon MN, et al. A common variant in the FTO gene is associated with body mass index and predisposes to childhood and adult obesity. Science 2007;316:889-94.

3. Sonestedt E, Gullberg B, Ericson U, Wirfalt E, Hedblad B, Orho-Melander M. Association between fat intake, physical activity and mortality depending on genetic variation in FTO. Int J Obes (Lond) 2011;35:1041-9.

4. Hakanen M, Raitakari OT, Lehtimaki T, et al. FTO genotype is associated with body mass index after the age of seven years but not with energy intake or leisure-time physical activity. J Clin Endocrinol Metab 2009;94:1281-7.

5. Kaakinen M, Laara E, Pouta A, et al. Life-course analysis of a fat mass and obesityassociated (FTO) gene variant and body mass index in the Northern Finland Birth Cohort 1966 using structural equation modeling. Am J Epidemiol 2010;172:653-65.

6. Mook-Kanamori DO, Ay L, Hofman A, et al. No association of obesity gene FTO with body composition at the age of 6 months. The Generation R Study. J Endocrinol Invest 2011;34:16-20.

7. Sovio U, Mook-Kanamori DO, Warrington NM, et al. Association between common variation at the FTO locus and changes in body mass index from infancy to late childhood: the complex nature of genetic association through growth and development. PLoS Genet 2011;7:e1001307.

8. Eriksson B, Lof M, Forsum E. Body composition in full-term healthy infants measured with air displacement plethysmography at 1 and 12 weeks of age. Acta Paediatr 2010;99:563-8.

9. Lopez-Bermejo A, Petry CJ, Diaz M, et al. The association between the FTO gene and fat mass in humans develops by the postnatal age of two weeks. J Clin Endocrinol Metab 2008;93:1501-5.

10. Jörgensen C. Fetometri och graviditetsbestämning. Obstetriska ultraljud. Västerås: Västra Aros tryckeri AB, 1997:37-44.

11. Kleinbaum DG, Kupper LL, Nizam A, Muller KE. Applied regression analysis and other multivariable methods: Thomson, 2008.

12. Jacobsson JA, Danielsson P, Svensson V, et al. Major gender difference in association of FTO gene variant among severely obese children with obesity and obesity related phenotypes. Biochem Biophys Res Commun 2008;368:476-82.

13. Elks CE, Loos RJ, Sharp SJ, et al. Genetic markers of adult obesity risk are associated with greater early infancy weight gain and growth. PLoS Med 2010;7:e1000284.

14. Ellis KJ, Yao M, Shypailo RJ, Urlando A, Wong WW, Heird WC. Body-composition assessment in infancy: air-displacement plethysmography compared with a reference 4compartment model. Am J Clin Nutr 2007;85:90-5.

15. Fields DA, Gilchrist JM, Catalano PM, Gianni ML, Roggero PM, Mosca F. Longitudinal body composition data in exclusively breast-fed infants: a multicenter study. Obesity (Silver Spring) 2011;19:1887-91.

16. Niklasson A, Albertsson-Wikland K. Continuous growth reference from 24th week of gestation to 24 months by gender. BMC Pediatr 2008;8:8. 
17. Harvey NC, Poole JR, Javaid MK, et al. Parental determinants of neonatal body composition. J Clin Endocrinol Metab 2007;92:523-6.

18. Ong K, Loos R. Rapid infancy weight gain and subsequent obesity: Systematic reviews and hopeful suggestions. Acta Paediatr 2006;95:904-8. 